\title{
The Measurement of High-Density Lipoprotein Mediated Cholesterol Efflux from Macrophage Cells by Liquid Chromatography Tandem Mass Spectrometry
}

\author{
Mo Wanga,c Hanbang Guo ${ }^{b}$ Siming Wang ${ }^{b}$ Ruiyue Yang ${ }^{b}$ Hongxia Li ${ }^{b}$ \\ Haijian Zhaoc Shu Wang ${ }^{\mathrm{b}}$ Jun Dong ${ }^{\mathrm{b}}$ Wenxiang Chen ${ }^{\mathrm{a}, \mathrm{b}, \mathrm{c}}$
}

${ }^{a}$ Graduate School of Peking Union Medical College and Chinese Academy of Medical Sciences, ${ }^{\text {TT The }}$ Key Laboratory of Geriatrics, Beijing Hospital and Beijing Institute of Geriatrics, 'Beijing Hospital and National Center for Clinical Laboratories, Beijing, China

\section{Key Words}

High-density lipoprotein - Macrophage - Cholesterol efflux - Mass spectrometry • Cardiovascular diseases

\begin{abstract}
Background: Studies have shown a negative association between macrophage cholesterol efflux and atherosclerotic cardiovascular diseases (CVD). However, the current methods for measuring cholesterol efflux require a radioactive tracer and involve a variety of cell treatments, making the measurement of macrophage cholesterol efflux impractical for use in clinical laboratories. In this study, we developed a non-radioactive and precise LC/MS/MS method for the measurement of high-density lipoprotein (HDL) mediated cholesterol efflux from J774 macrophages. Methods: $\mathbf{3 7 7 4}$ cells were seeded on 12-well plates at a density of $1.5 \times 10^{5}$ cells $/ \mathrm{ml}$ in $\mathrm{H}$-DMEM medium, and when the cells were approximately $80 \%$ confluent, they were incubated with $\mathrm{H}$-DMEM medium containing $2 \%$ FBS, $0.5 \mu \mathrm{g} / \mathrm{ml}$ ACAT inhibitor Sandoz 58-035, and $20 \mu \mathrm{g} / \mathrm{ml}\left[3,4-{ }^{13} \mathrm{C}\right]$ cholesterol for $6 \mathrm{~h}$. After washing and equilibrating the cells, HDL samples were added at a final concentration of $7 \%$ and incubated for $8 \mathrm{~h}$. The cells were lysed, and $\left[3,4-{ }^{13} \mathrm{C}\right]$ cholesterol and cholesterol were measured by LC/MS/MS. Cholesterol efflux was expressed as the percent decrease of cell $\left[3,4-{ }^{13} \mathrm{C}\right]$ cholesterol mass during the incubation. Results: When incubated with $\left[3,4-{ }^{13} \mathrm{C}\right]$ cholesterol enriched $\mathrm{J} 774$ cells, HDL mediated higher cell cholesterol efflux than influx compared to serum and isolated LDL; therefore, HDL was used as the extracellular acceptor. The results from healthy volunteers showed that the rate of cholesterol efflux was negatively correlated with weight, $\mathrm{BMI}$, blood pressure, and $\mathrm{FER}_{\mathrm{HDL}}$ and positively correlated with HDL-C, HDL2-C, and apoAI levels. Conclusions: A LC/MS/MS method for the measurement of HDL mediated cholesterol efflux from macrophage cells has been
\end{abstract}


established. This method is non-radioactive, precise and reliable and is potentially useful for the assessment of HDL function and cardiovascular disease risks.

Copyright (C) 2014 S. Karger AG, Basel

\section{Introduction}

Epidemiologic and interventional studies have clearly established an inverse association between plasma levels of high-density lipoprotein (HDL) cholesterol (HDL-C) and the incidence of atherosclerotic cardiovascular diseases (CVD) [1]. The inverse correlation between the HDL-C level and CVD risk is maintained even in patients with low low-density lipoprotein (LDL) cholesterol (LDL-C) concentrations [2]. However, efforts to increase HDL-C did not achieve consistent results, and high HDL-C concentrations are not always associated with protection against atherosclerosis [3]. Furthermore, rare or common mutations that relate to low HDL-C levels did not show significant associations with CVD [4]. Therefore, studies suggest that simply measuring HDL-C does not provide a reliable prediction of HDL's beneficial value. When assessing the benefits of existing and novel therapies that target HDL, one must consider other parameters that reflect HDL function besides the simple measurement of changes in plasma HDL-C.

The atheroprotective effect of HDL is mainly considered to be through the removal of cholesterol from peripheral tissues back to the liver for excretion through the reverse cholesterol transport (RCT) process [5, 6]. The capacity of HDL to accept cholesterol from macrophages, a metric of HDL function, has been recently shown to bear a strong inverse relation with atherosclerosis. A previous study showed that apolipoprotein (apo) B-depleted serum from individuals with similar levels of HDL-C or apoA-I may have different capacities to remove cholesterol from macrophages, and the cholesterol efflux capacity was significantly correlated with the concentration of pre $\beta-1$ HDL [7]. Khera et al. [8] measured the HDL mediated cholesterol efflux capacity from macrophage cells in healthy volunteers and in patients undergoing angiography. They found that the ability of HDL to promote cholesterol efflux from macrophages was strongly and inversely associated with both subclinical atherosclerosis and obstructive coronary artery disease. These associations persisted after adjusting for traditional cardiovascular risk factors, including the levels of HDL-C and apoA-I. In addition, HDL from cholesteryl ester transfer protein (CETP) deficient subjects, subjects treated with a high dose of CETP inhibitor (torcetrapib) or subjects with metabolic syndrome treated with pioglitazone showed increased HDL mediated cholesterol efflux $[9,10]$. These novel results added to the increasing evidence that measures of HDL function, such as its efflux capacity, can be useful when assessing an individual's CVD risk.

The widely used method for the measurement of cholesterol efflux potential is the isotopic assay established by de la LleraMoya et al. [7]. In this method, donor cells, such as hepatoma cells, fibroblasts, or macrophages, were first loaded with a radioactive tracer, ${ }^{3} \mathrm{H}$ - or ${ }^{14} \mathrm{C}$-cholesterol and then incubated in a medium containing a cholesterol "acceptor" (diluted human serum or HDL). After multiple washings, scintigraphy quantified the radioactivity present in the medium and in the donor cells. Cholesterol efflux was then expressed as the amount of radioactive cholesterol released into the medium divided by the total signal. Although these assays have played an important role in elucidating the mechanisms of cholesterol efflux from cells [11], a protocol using radio-labelled cholesterol makes it unsuitable for a wide range of clinical applications. Furthermore, the current methods involve a variety of different treatments to the cells, methodological studies are needed to define the experimental conditions to decrease the variability of future studies using these methods.

In this study, we used the stable isotope $\left[3,4-{ }^{13} \mathrm{C}\right]$ cholesterol as a tracer, investigated the conditions of cholesterol enrichment, tested the abilities of different acceptors to produce cholesterol flux, and established a liquid chromatography tandem mass spectrometry (LC/ MS/MS) method for the measurement of HDL mediated cholesterol efflux potential. This 
method is non-radioactive, precise, and reliable and should provide a useful tool for the clinical measurement of cholesterol efflux.

\section{Materials and Methods}

\section{Materials and reagents}

The J774 murine macrophage cell line was purchased from Peking Union Medical College, China. Fetal bovine serum (FBS) was purchased from Hyclone (Waltham, MA, USA). DNase was purchased from New England Biolabs (Beverly, MA, USA). High Dulbecco's minimal essential medium (H-DMEM), penicillin and streptomycin were products of Gibco BRL (Gaithersburg, MD, USA). Tissue culture plastic-ware was purchased from Corning (Corning, NY, USA). Fatty-acid-free bovine serum albumin (BSA), trypsin, polyethylene glycol (PEG) 6000, Sandoz 58-035, sodium cholate and cholesterol were all purchased from Sigma-Aldrich (St. Louis, MO, USA). HPLC-grade isopropanol and methanol were products of Thermo Fisher Scientific (Newark, DE, USA). $\left[3,4-{ }^{13} \mathrm{C}\right]$ cholesterol, with isotopic purities of $99 \%$, was purchased from Cambridge Isotope Laboratories (Andover, MA, USA). Methyl- $\beta$-cyclodextrin (M $\beta$-CD) was purchased from Beifang Technology (Beijing, China). The cholesterol used in the calibration solutions was cholesterol reference material SRM 911b (National Institute of Standards and Technology, Gaithersburg, MD, USA).

\section{Preparation of lipoproteins and human sera}

For method development and validation, serum samples were collected from leftover patient specimens in the department of laboratory medicine of Beijing Hospital. The specimens in the clinical laboratory were bar coded, and the vials were labelled without information relating to the specimen identities. For isolation of LDL and HDL fractions, patient serum samples were pooled and mixed. LDL (d=1.006-1.063 g/ml) fractions were isolated by sequential ultracentrifugation as described previously [12]. The HDL fraction was prepared by precipitating apoB-containing lipoproteins using polyethylene glycol (PEG) 6000[13]. For the measurement of cholesterol efflux, serum samples from healthy volunteers were collected, and HDL fractions were separated. Briefly, aliquots of $0.5 \mathrm{ml}$ of serum samples were pipetted into 2-ml vials, followed by the addition of $0.2 \mathrm{ml}$ of $20 \%$ PEG[13]. The vials were then vortexed and allowed to stand at room temperature for $15 \mathrm{~min}$ followed by centrifugation. An aliquot of $0.5 \mathrm{ml}$ of the supernatant was transferred to another vial for efflux measurement. The presence of PEG does not alter the efflux capacity of the extracellular acceptors. Because of the dilution of the sera by the precipitation reagents, $7 \%$ of the apoB-depleted serum is equivalent to $5 \%$ whole serum [8].

This study has been reviewed and approved by the Ethics Committee of Beijing Hospital. All study volunteers were made aware of the intended use of their sample in writing and provided written consent.

\section{Cell culture conditions and selection of extracellular acceptors}

The $\left[3,4-{ }^{13} \mathrm{C}\right]$ cholesterol solution was prepared by dissolving $\left[3,4-{ }^{13} \mathrm{C}\right]$ cholesterol in $20 \% \mathrm{M} \beta-\mathrm{CD}$. To investigate the changes of cell cholesterol and cholesteryl esters (CE) after labelling and enrichment with $\left[3,4-{ }^{13} \mathrm{C}\right]$ cholesterol, cholesterol solutions with different concentrations were added to J774 cells with and without the ACAT inhibitor Sandoz 58-035, and after incubation, cell free cholesterol (FC) and CE levels were measured with LC/MS/MS. To determine the suitable concentration of Sandoz 58-035, J774 cells were incubated with $20 \mu \mathrm{g} / \mathrm{ml}\left[3,4-{ }^{13} \mathrm{C}\right]$ cholesterol for $2,4,8$, and $12 \mathrm{~h}$ in the presence of different concentrations of Sandoz 58-035, and the cell $\left[3,4-{ }^{13} \mathrm{C}\right]$ cholesterol concentration and CE formation were examined. To evaluate the effects of ACAT inhibition and FC accumulation on cell viability, J774 cells were incubated with $0.5 \mu \mathrm{g} / \mathrm{ml}$ Sandoz 58-035 and different concentrations of $\left[3,4-{ }^{13} \mathrm{C}\right]$ cholesterol for $6 \mathrm{hr}$, and cell viability was estimated by a colorimetric assay using the MTS test. For the selection of extracellular acceptors, J774 cells were labelled with $\left[3,4-{ }^{13} \mathrm{C}\right]$ cholesterol and incubated with human serum, isolated LDL, and HDL fractions respectively, and the cholesterol efflux and influx were measured. The measurement of cell cholesterol and $\left[3,4-{ }^{13} \mathrm{C}\right]$ cholesterol by LC/MS/MS using stigmasterol as an internal standard was also optimised. All of the analyses in the method development and validation were performed in triplicate.

LC/MS/MS analysis of macrophage cholesterol efflux in $\left[3,4-{ }^{13} \mathrm{C}\right]$ cholesterol labelled $J 774$ cells

J774 cells were seeded on 12-well plates at a concentration of $1.5 \times 10^{5}$ cells $/ \mathrm{ml}$ in H-DMEM growth medium 1 day before uptake experiments. When the cells were approximately $80 \%$ confluent, they were 
treated with medium containing $2 \%$ FBS, $0.5 \mu \mathrm{g} / \mathrm{ml}$ Sandoz 58-035, and $20 \mu \mathrm{g} / \mathrm{ml}\left[3,4-{ }^{13} \mathrm{C}\right]$ cholesterol for $6 \mathrm{~h}$. The cells were washed with phosphate-buffered saline and equilibrated in medium containing $0.2 \%$ BSA and $0.5 \mu \mathrm{g} / \mathrm{ml}$ Sandoz 58-035. Individual HDL samples were then added to duplicate wells at a final concentration of $7 \%$ and incubated for $8 \mathrm{~h}\left(\mathrm{~T}_{8}\right)$, and control cells remained in the original medium $\left(\mathrm{T}_{0}\right)$. After washing with phosphate-buffered saline, the cells were lysed and lipids extracted by adding $0.4 \mathrm{ml}$ of a $1 \%$ sodium cholate solution containing $10 \mathrm{U} / \mathrm{ml}$ DNase, mixing and gently shaking for $1 \mathrm{hr}$ at room temperature. Cell proteins were measured by the bicinchoninic acid (BCA) method [14]. Cell cholesterol and $\left[3,4-{ }^{13} \mathrm{C}\right]$ Cholesterol were measured by our previously described LC/MS/MS method [15] with modifications as described below.

Briefly, an aliquot $0.05 \mathrm{~mL}$ of cell lysates or the cholesterol calibrators $(1,2,4,6,8 \mathrm{mg} / \mathrm{dl})$ were transferred into a $2-\mathrm{ml}$ vial, and $0.5 \mathrm{~mL}$ of $8.9 \mathrm{~mol} / \mathrm{L}$ potassium hydroxide-ethanol $(10: 90, \mathrm{v} / \mathrm{v})$ was added. The mixture was incubated at $50^{\circ} \mathrm{C}$ for $2 \mathrm{~h}$ for hydrolysis of cholesteryl esters followed by the addition of $0.5 \mathrm{~mL}$ of water and $1 \mathrm{ml}$ of hexane containing stigmasterol as an internal standard. The vials were vortexed for $15 \mathrm{~min}$ and then aliquots of $0.6 \mathrm{~mL}$ hexane phase were transferred to another vial, dried under vacuum, oxidised by chromic acid-sulphuric acid, and analysed by LC/MS/MS [15].

The LC separation was performed on a Waters Symmetry C18 column $(4 \mu \mathrm{m}, 2.1 \times 150 \mathrm{~mm})$ with a mobile phase of methanol-isopropanol (40:60, v/v) at a flow rate of $0.3 \mathrm{~mL} / \mathrm{min}$. Tandem mass spectrometry (MS/MS) was carried out on an API 4000 triple quadruple mass spectrometer (Sciex Applied Biosystems). MS detection was performed with atmospheric pressure chemical ionisation (APCI) in the positive ion mode and multiple reaction monitoring (MRM) mode. The curtain gas, nebulizer gas and collision gas were nitrogen at settings of 30,65 and 5 psi, respectively. The corona current was set at $5 \mu \mathrm{A}$, and the source temperature was maintained at $450^{\circ} \mathrm{C}$. The declustering potential, entrance potential, collision energy, and collision exit potential were set at $82 \mathrm{~V}, 4 \mathrm{~V}, 26 \mathrm{eV}$ and $6 \mathrm{~V}$, respectively. The dwell time was $0.2 \mathrm{~s}$ for MRM.

Aliquots of $2 \mu \mathrm{L}$ of the prepared calibrators or samples were injected with an auto sampler. The transitions of $(\mathrm{M}+\mathrm{H})^{+} \rightarrow\left[(\mathrm{M}+\mathrm{H})^{+}-\mathrm{H}_{2} \mathrm{O}\right]$ at $\mathrm{m} / \mathrm{z} 401 \rightarrow 383, \mathrm{~m} / \mathrm{z} 399 \rightarrow 381$ and $425.4 \rightarrow 83$ were monitored for $\left[3,4-{ }^{13} \mathrm{C}\right]$ cholesterol, unlabelled cholesterol and stigmasterol, respectively, as their oxidation products. The calibration curve was generated using a linear regression of the peak area ratios of unlabelled cholesterol to stigmasterol, which was used to calculate the cell $\left[3,4-{ }^{13} \mathrm{C}\right]$ cholesterol and cholesterol concentrations. Cholesterol mass was expressed as $\mu \mathrm{g}$ cholesterol/mg protein. The cholesterol efflux mediated by HDL was calculated by the following equation. To correct for inter-assay variations, a pooled HDL control was included in each run, and values for individual HDL samples were normalised to this pooled value in subsequent analyses.

Cholesterol Efflux $=\left(\right.$ Cell $\left[3,4-{ }^{13} \mathrm{C}\right]$ cholesterol Mass $_{\mathrm{T} 0}$-Cell $\left[3,4-{ }^{13} \mathrm{C}\right]$ cholesterol Mass $\left.\mathrm{T8}\right) /$ Cell $\left[3,4-{ }^{13} \mathrm{C}\right]$ cholesterol Mass $_{\mathrm{T} 0} \times 100 \%$

Measurement of cholesterol efflux in healthy subjects

The LC/MS/MS method was applied to 49 apparently healthy volunteers (35 males and 14 females) aged 23 to 76 years old. Body weight, height, and blood pressure were measured. Serum total cholesterol (TC), triglyceride (TG), apoAI, apoB, and glucose (GLU) were analysed by assay kits from Sekisui Medical Technologies (Osaka, Japan) on a Hitachi 7180 analyser. Cholesterol levels of HDL, LDL and their subfractions were measured by our ultracentrifugation/HPLC method [16, 17]. The fractional cholesterol esterification rate in serum HDL $\left(\mathrm{FER}_{\mathrm{HDL}}\right.$ ) was measured by HPLC as previously described [18].The Pearson correlation was used to test the relationship between cholesterol efflux and CVD risk factors from data that demonstrated normal distribution, while Spearman's correlation was used for correlation analysis when the distribution of data were skewed. Statistical significance was defined as $P<0.05$. All of the statistical analyses were performed using SPSS 17.0 (SPSS Inc., Chicago, IL).

\section{Results}

Enrichment of J774 cells with FC in the presence of an ACAT inhibitor

The design of the experiment to quantitate cholesterol flux is greatly influenced by the cholesterol content of the cells at the start of the experimental period. Some previous studies 
Fig. 1. Changes in cell TC, FC and CE after J774 cells were incubated with cholesterol in the absence (A) and presence (B) of acyl coenzyme A: cholesterol acyltransferase (ACAT) inhibitor. Mouse J774 cells were cholesterol-enriched for $8 \mathrm{~h}$ with H-DMEM medium containing $2 \%$ FBS and different concentrations of cholesterol in the absence (A) and presence (B) of the ACAT inhibitor Sandoz 58-035. Cell lipids were extracted, and TC and FC were measured by LC/MS/MS. CE was calculated by subtracting FC from TC. Cell protein was measured by the BCA method. Values of TC, FC and CE are means from triplicate wells.

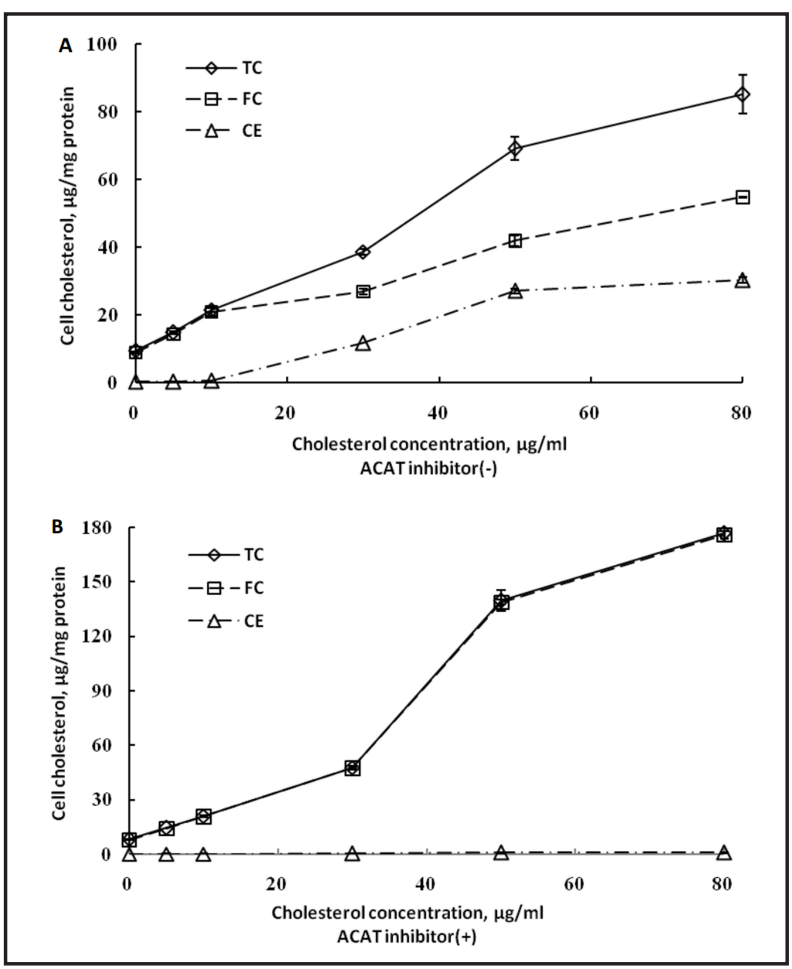

Fig. 2. $\left[3,4-{ }^{13} \mathrm{C}\right]$ cholesteryl esterification in J774 cells was inhibited by an ACAT inhibitor during incubation. J774 cells were incubated with H-DMEM medium containing $2 \%$ FBS and $20 \mu \mathrm{g} / \mathrm{ml}\left[3,4-{ }^{13} \mathrm{C}\right]$ cholesterol in the presence of different concentrations of Sandoz 58-035 for 2, 4, 8, and $12 \mathrm{~h}$. Cell lipids were extracted, and $\left[3,4-{ }^{13} \mathrm{C}\right]$ labelled TC and FC were measured by LC/MS/MS. $\left[3,4-{ }^{13} \mathrm{C}\right]$ labeled CE was calculated by subtracting FC from TC. Cell protein was measured by the BCA method.

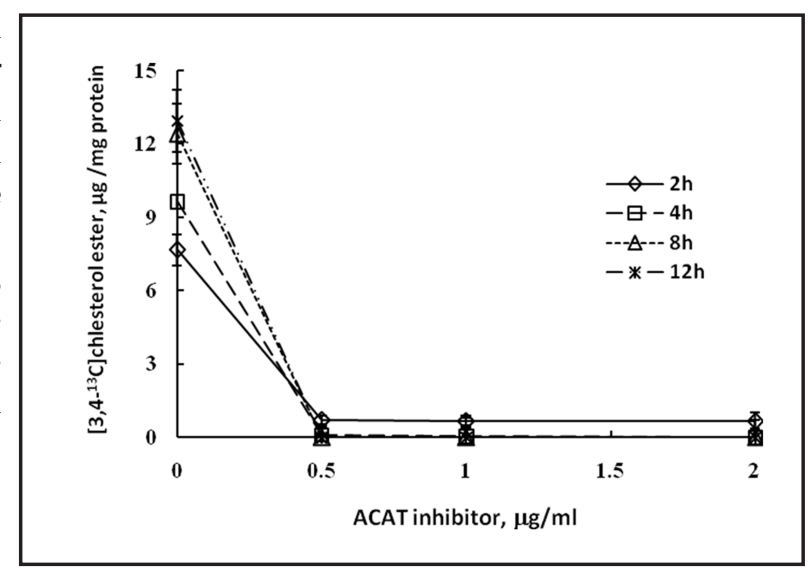

enriched the cells with cholesterol by growing them in the presence of LDL, acetyl-LDL, oxidised-LDL, or cholesterol-rich dispersions to produce a foam cell phenotype. However, the presence of large stores of CE can complicate efflux determinations. In this study, we labelled and enriched J774 cells with $\left[3,4-{ }^{13} \mathrm{C}\right]$ cholesterol. As shown in Fig. 1, almost all of the cholesterol that existed in the J774 cells was in the state of free cholesterol. When the J774 cells were incubated with increasing concentrations of FC, cell CE were synthesised by the enzyme acyl coenzyme A: cholesterol acyltransferase (ACAT). However, the esterification of FC was effectively eliminated if cells were incubated together with the ACAT inhibitor Sandoz 58-035. To reduce the concentrations of FC and Sandoz 58-035 added to cells, and to minimise cell toxicity, a final concentration of $20 \mu \mathrm{g} / \mathrm{ml}$ cholesterol was incubated with the cells in the presence of 0, 0.5, 1.0, and $2.0 \mu \mathrm{g} / \mathrm{ml}$ of Sandoz 58-035 for 1, 2, 4, 8, and 12 $h$, respectively. The results suggested that cell $\left[3,4-{ }^{13} \mathrm{C}\right]$ cholesterol increased with increased incubation time $(0-4 \mathrm{~h})$ but remained almost unchanged when the incubation time further increased (4-12 h). Therefore, a 6-hr incubation time was used in the experiment. At the end of loading, the intracellular mass of $\left[3,4-{ }^{13} \mathrm{C}\right]$ cholesterol was twofold greater than that of unlabelled cholesterol. As shown in Fig. 2, 0.5-2.0 $\mathrm{\mu g} / \mathrm{ml}$ Sandoz 58-035 effectively inhibited 
Fig. 3. Viability tests of J774 cells after incubation with different concentrations of $\left[3,4-{ }^{13} \mathrm{C}\right]$ cholesterol. $] 774$ cells were incubated with increasing concentrations of $[3,4$ $\left.{ }^{13} \mathrm{C}\right]$ cholesterol in the absence and presence of $0.5 \mu \mathrm{g} / \mathrm{ml}$ ACAT inhibitor Sandoz 58-035 for $6 \mathrm{~h}$. Cell viability was determined by MTS and is presented as the percent of control cells measured.

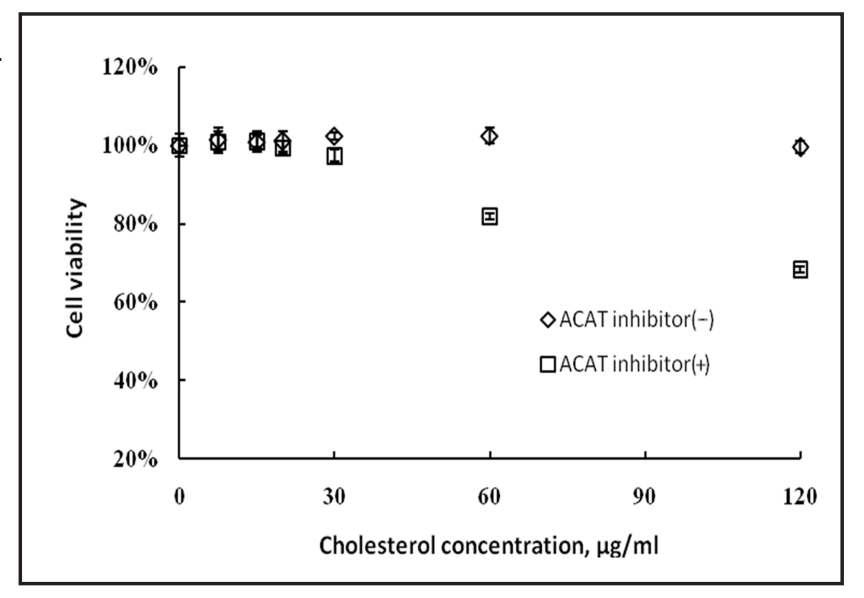

Fig. 4. Cell cholesterol efflux and influx after J774 cells were incubated with different concentrations of serum and isolated LDL and HDL fractions. J774 cells were treated with H-DMEM containing 2\% FBS, $0.5 \mu \mathrm{g} /$ ml ACAT inhibitor Sandoz 58-035 and 20 $\mu \mathrm{g} / \mathrm{ml}\left[3,4-{ }^{13} \mathrm{C}\right]$ cholesterol for $6 \mathrm{~h}$. After equilibration with $0.2 \% \mathrm{BSA}$, cells were incubated with different concentrations of serum (A), LDL (B), and HDL (C) for $8 \mathrm{hr}$. $0.5 \mu \mathrm{g} / \mathrm{ml}$ Sandoz 58-035 was present during the entire experimental process. Cell lipids were extracted, and $\left[3,4-{ }^{13} \mathrm{C}\right]$ cholesterol and cholesterol levels before and after incubation were measured by LC/MS/MS. Cholesterol efflux and influx were calculated as the changes in cell $\left[3,4-{ }^{13} \mathrm{C}\right]$ cholesterol and cholesterol mass during incubation.
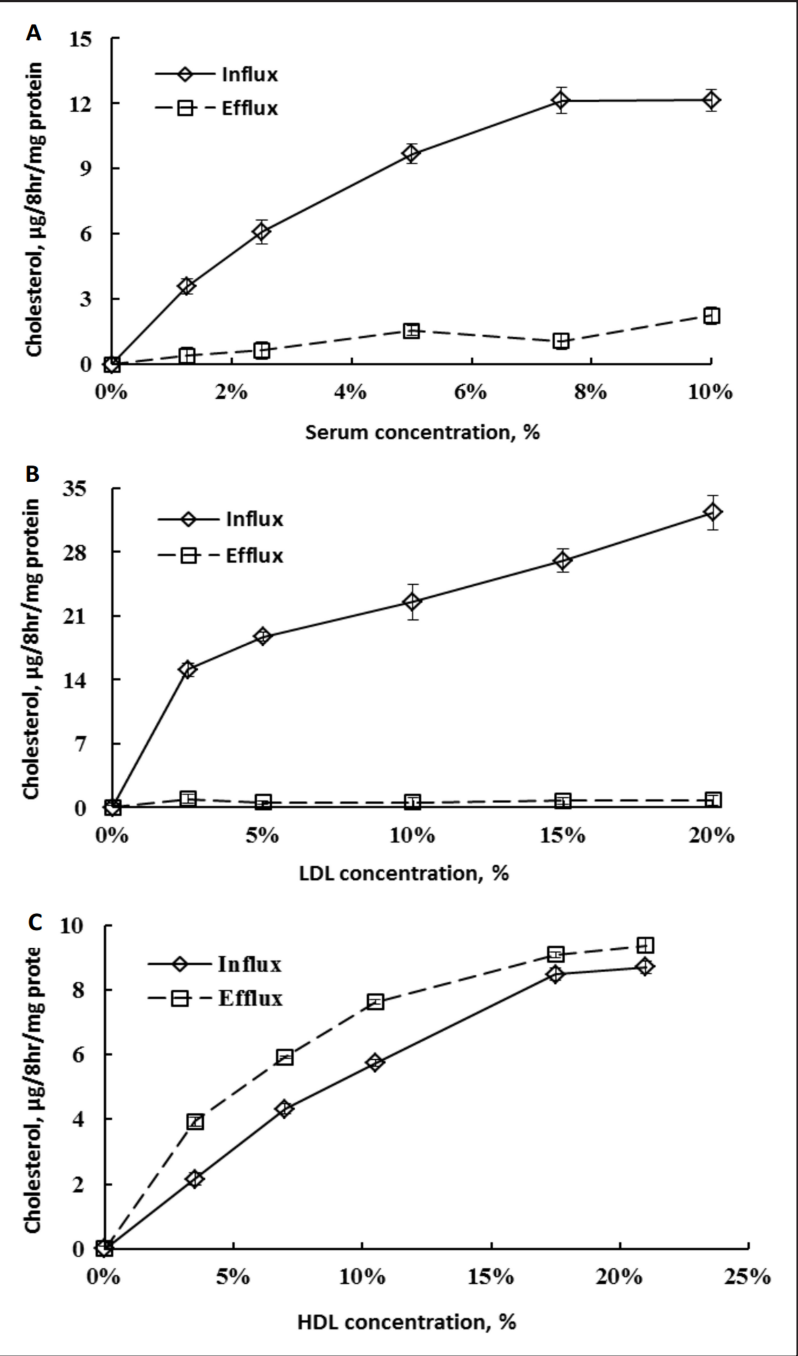

cell CE formation (CE was undetectable) when incubated with cells for more than $4 \mathrm{hr}$; therefore, $0.5 \mu \mathrm{g} / \mathrm{ml}$ Sandoz 58-035 was used in the experiment. Furthermore, cell viability was not affected when grown with $20 \mu \mathrm{g} / \mathrm{ml}$ cholesterol and $0.5 \mu \mathrm{g} / \mathrm{ml}$ Sandoz 58-035 for 6 h (Fig. 3). 
Fig. 5. Multiple reaction monitoring (MRM) mass spectrograms (A) and chromatograms (B) of oxidised cholesterol, [3,4$\left.{ }^{13} \mathrm{C}\right]$ cholesterol, and stigmasterol.

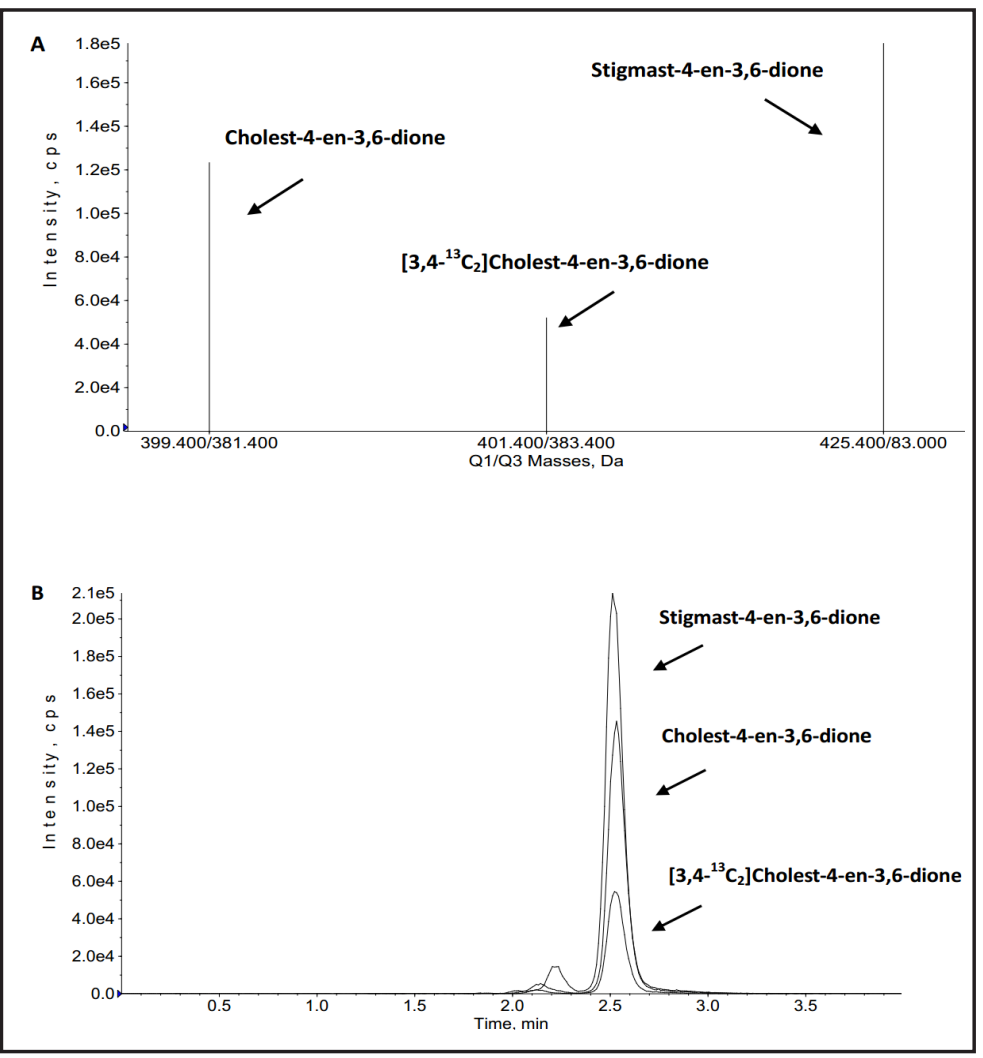

Selection of extracellular acceptors

A wide variety of the extracellular particles have been used to study specific parameters of the cholesterol flux process. To select appropriate extracellular acceptors, we incubated cells with human serum and isolated LDL and HDL fractions and quantitated the influence of each acceptor on cell cholesterol efflux as well as on the influx of cholesterol to cells. J774 cells were labelled and enriched with $\left[3,4-{ }^{13} \mathrm{C}\right]$ cholesterol in the presence of $0.5 \mu \mathrm{g} /$ $\mathrm{ml}$ Sandoz 58-035 and then incubated with medium containing different acceptors. As shown in Fig. 4A, when incubated with serum, there was a flux of free $\left[3,4-{ }^{13} \mathrm{C}\right]$ cholesterol out of the cell (efflux), while simultaneously there was movement of serum-derived FC and CE into the cell (influx), and the cholesterol influx was much greater than the efflux. As shown in Fig. $4 \mathrm{~B}$, incubating $\left[3,4-{ }^{13} \mathrm{C}\right]$ cholesterol enriched cells with LDL resulted in a significant increase in cell cholesterol mass (influx), but almost no efflux of cell cholesterol. As expected, cell cholesterol efflux was significantly higher than the influx when HDL was present as the acceptor at concentrations of $3.5 \%, 7.5 \%$ and $10 \%$, with cholesterol efflux and influx of $3.9 \pm 0.13$ vs $2.2 \pm 0.18,5.9 \pm 0.04$ vs $4.1 \pm 0.16$, and $7.6 \pm 0.06$ vs $5.7 \pm 0.11$, respectively (Fig. 4C). Therefore, individual HDL samples at a final concentration of $7 \%$ were used as the extracellular acceptor for the measurement of cholesterol efflux.

\section{LC/MS/MS analysis of unlabelled cholesterol and $\left[3,4^{-13} \mathrm{C}\right]$ cholesterol}

We have previously established HPLC and LC/MS/MS methods for the measurement of serum total cholesterol using stigmasterol and $\left[3,4-{ }^{13} \mathrm{C}\right]$ cholesterol, respectively, as internal standards $[15,19]$. Stigmasterol has been demonstrated to be an ideal internal standard with chemical and physical characteristics almost identical to those of cholesterol. Therefore, in this study, we established an LC/MS/MS method for the measurement of both $\left[3,4-{ }^{13} \mathrm{C}\right]$ cholesterol and unlabelled cholesterol by using stigmasterol as the internal standard and the conversion of cholesterol, $\left[3,4-{ }^{13} \mathrm{C}\right]$ cholesterol, and stigmasterol to cholest-4-en-3,6dione with chromic acid. Fig. 5A shows the ionisation and fragmentation of the oxidised cholesterol, $\left[3,4-{ }^{13} \mathrm{C}\right]$ cholesterol and stigmasterol. The transitions of $\left[(\mathrm{M}+\mathrm{H})^{+} \rightarrow\left[(\mathrm{M}+\mathrm{H})^{+}-\mathrm{H}_{2} \mathrm{O}\right]\right.$ 
Table 1. Parameters of standard curves between the cholesterol concentration and peak area ratio of cholesterol to the internal standard

\begin{tabular}{lcc}
\hline & Average & Range \\
\hline Slope & 0.607 & $0.579-0.663$ \\
Intercept & -0.003 & $-0.042-0.022$ \\
Correlation coefficient $\left(\mathrm{r}^{2}\right)$ & 0.9998 & $0.9996-0.9999$ \\
Standard error $(\mathrm{SE})$ of the y estimate & 0.0016 & $0.001-0.002$ \\
\hline
\end{tabular}

Table 2. The mean / median and standard deviation of the parameters and correlation with HDL mediated cholesterol efflux in 49 healthy subjects. *skewed distribution. The median was used instead of the mean, and the Spearman correlation was applied for correlation analysis

\begin{tabular}{|c|c|c|c|c|c|c|}
\hline & \multirow{2}{*}{ Mean/Median } & \multirow{2}{*}{ SD } & \multirow[t]{2}{*}{ Min } & \multirow[t]{2}{*}{ Max } & \multicolumn{2}{|c|}{$\begin{array}{l}\text { Correlation with the rate } \\
\text { of cholesterol efflux }\end{array}$} \\
\hline & & & & & $\mathrm{r}$ & \\
\hline Age, years & 46 & 13 & 23 & 76 & 0.033 & $>0.05$ \\
\hline Height, m & 1.69 & 0.07 & 1.40 & 1.82 & -0.152 & $>0.05$ \\
\hline Weight, kg & 67.6 & 49.0 & 49.0 & 94.0 & -0.329 & $<0.05$ \\
\hline BMI, $\mathrm{kg} / \mathrm{m}^{2}$ & 23.7 & 3.0 & 19.1 & 29.1 & -0.328 & $<0.05$ \\
\hline $\mathrm{SBP}, \mathrm{mmHg}$ & 122 & 15 & 100 & 160 & -0.283 & $<0.05$ \\
\hline $\mathrm{DBP}^{*}, \mathrm{mmHg}$ & 80 & 10 & 60 & 100 & -0.346 & $<0.05$ \\
\hline Glu*, mmol/L & 5.25 & 1.26 & 4.41 & 12.07 & -0.159 & $>0.05$ \\
\hline apoAI, mg/dL & 132.9 & 17.3 & 92.3 & 183.4 & 0.426 & $<0.01$ \\
\hline apoB, mg/dL & 97.5 & 18.3 & 57.9 & 145.1 & -0.043 & $>0.05$ \\
\hline $\mathrm{TC}, \mathrm{mmol} / \mathrm{L}$ & 4.84 & 0.86 & 3.25 & 7.38 & 0.177 & $>0.05$ \\
\hline $\mathrm{TG}^{*}, \mathrm{mmol} / \mathrm{L}$ & 1.16 & 1.14 & 0.40 & 7.73 & -0.026 & $>0.05$ \\
\hline HDL-C, mmol/L & 1.32 & 0.32 & 0.67 & 2.22 & 0.458 & $<0.01$ \\
\hline HDL2-C, mmol/L & 0.70 & 0.26 & 0.32 & 1.65 & 0.459 & $<0.01$ \\
\hline HDL3-C, mmol/L & 0.56 & 0.09 & 0.35 & 0.81 & 0.141 & $>0.05$ \\
\hline LDL-C, mmol/L & 2.95 & 0.71 & 1.55 & 4.7 & -0.059 & $>0.05$ \\
\hline LDLa-C, mmol/L & 2.34 & 0.67 & 0.5 & 4.07 & 0.018 & $>0.05$ \\
\hline LDLb-C, mmol/L & 0.48 & 0.19 & 0.2 & 0.95 & -0.135 & $>0.05$ \\
\hline FERHDL, \%/hr & 18.0 & 0.1 & 0.6 & 36.7 & -0.437 & $<0.01$ \\
\hline Cholesterol Efflux, \% & 24.55 & 3.9 & 16.74 & 36.1 & - & - \\
\hline
\end{tabular}

at $\mathrm{m} / \mathrm{z} 399.4 \rightarrow 381.4, \mathrm{~m} / \mathrm{z} 401.4 \rightarrow 383.4$ and $425.4 \rightarrow 83.0$ were monitored for cholesterol, $\left[3,4-{ }^{13} \mathrm{C}\right]$ cholesterol and stigmasterol, respectively, as their oxidation products. The oxidation and the MRM detection effectively eliminated most of the possible interferences. Cholesterol, $\left[3,4-{ }^{13} \mathrm{C}\right]$ cholesterol and stigmasterol were eluted at the same time by a mobile phase of isopropanol-methanol (40:60, v/v), and the total run time was approximately 3 min (Fig. $5 B)$.

Cholesterol and $\left[3,4-{ }^{13} \mathrm{C}\right]$ cholesterol were all calculated by using cholesterol as the calibrator. The linear correlation between cholesterol concentration $(x)$ (the five calibrators, each in duplicate) and the peak area ratio ( $y$ ) of cholesterol to stigmasterol in 5 analytical runs were assessed by linear regression analysis. The slopes, intercepts, correlation coefficients, and standard errors of the $y$ estimate are shown in Table 1 . The total coefficient correlations were below $2 \%$ and $7 \%$ for the LC/MS/MS measurement of cell cholesterol and the HDL mediated macrophage cholesterol efflux, respectively.

\section{Measurement of HDL mediated cholesterol efflux in healthy subjects}

This method was applied to 49 apparently healthy volunteers (35 males and 14 females). These subjects had HDL-C and TG levels of 0.67-2.22 mmol/L and 0.40-7.73 $\mathrm{mmol} / \mathrm{L}$, respectively. The HDL mediated cholesterol efflux showed a normal distribution and the average rate was $24.6 \pm 3.9 \%$. Correlations between the rate of cholesterol efflux and other examined parameters are shown in Table 2. The results indicated that HDL mediated cholesterol efflux was positively correlated with HDL-C $(\mathrm{r}=0.458, P=0.006)$, HDL2-C ( $\mathrm{r}=$ $0.459, P=0.002)$ and apoAI $(\mathrm{r}=0.426, P=0.008)$, while no correlation was found between cholesterol efflux and HDL3-C $(\mathrm{r}=0.141, P>0.05)$. Cholesterol efflux was negatively correlated with body weight $(\mathrm{r}=-0.329, P<0.05)$, BMI $(\mathrm{r}=-0.328, P<0.05)$, and blood pressure $(\mathrm{r}=$ -0.283 and $-0.346, P<0.05$, for SBP and DBP, respectively). Significant negative associations were also observed between HDL mediated cholesterol efflux and $\mathrm{FER}_{\mathrm{HDL}}(\mathrm{r}=-0.437, P<0.01)$, a predictor of HDL and LDL particle sizes $[18,20]$. No associations were found between the rate of cholesterol efflux and cholesterol levels in LDL and subfractions and apoB. 


\section{Discussion}

A link between the in vitro efflux of cholesterol from macrophages and atherosclerosis has recently been established by studies demonstrating a negative correlation between cholesterol efflux from J774 cells and coronary artery disease as measured by either carotid intima-media thickness or coronary angiography [8]. Therefore, the availability of a nonradioactive and reliable technique for measuring cholesterol efflux could be of significant importance for CVD risk assessment. However, the use of radiolabelled cholesterol in the current methods makes it inconvenient to use in clinical laboratories for screening large numbers of individual specimens. In addition, results from the current methods are influenced by a variety of different treatments to the cells, e.g., the loading of the cells, the status of cell cholesterol content, the combination of efflux pathways, the presence or absence of an ACAT inhibitor, the type and concentration of extracellular acceptors, and the specificity of the method for measuring isotope labelled cholesterol. Some investigators have substituted a fluorescent mimic of cholesterol for the radiolabelled cholesterol and quantitated efflux by fluorescent measurements [21, 22]. However, the structure and behaviour of the fluorescent sterols are not the same as cholesterol, and the rates of efflux were much higher or lower than those of ${ }^{3} \mathrm{H}$-cholesterol. Brown et al. [23] used [d7]-cholesterol for labelling J774 cells and a mass spectrometry-based assay to measure cholesterol efflux from J774 cells to HDL. To increase the measurement sensitivity, [d7]cholesterol and cholesterol were derivatised to acetylated cholesterol and accurately measured by directinfusion ESI-MS/MS. In our study, we investigated the loading of $\left[3,4-{ }^{13} \mathrm{C}\right]$ cholesterol to J774 cells, the inhibition of cholesterol esterification within the cells, cell viability, and extracellular acceptors and used a different LC/MS/MS approach for the measurement of cell cholesterol and $\left[3,4-{ }^{13} \mathrm{C}\right]$ cholesterol levels, and established a simple and nonradioactive method for screening cholesterol efflux potentials of individual HDL samples.

The initial cell cholesterol status and content were not only important for cell viability and the flux patterns between cells and medium but also for the accurate quantification by LC/MS/MS. Cholesterol efflux assays traditionally involve loading cells with radiolabelled cholesterol by adding radiolabelled cholesterol to medium containing acetylated LDL in the presence or absence of ACAT inhibitors [24]. However, preparation of acetylated LDL is tedious, and the existence of radiolabelled CE complicates the determination of the fractional release of labelled cholesterol from the cells. In our study, by dissolving $\left[3,4-{ }^{13} \mathrm{C}\right]$ cholesterol in $\mathrm{M} \beta-\mathrm{CD},\left[3,4-{ }^{13} \mathrm{C}\right]$ cholesterol solutions were directly added to the cell medium to load and enrich J774 cells in the presence of the ACAT inhibitor Sandoz 58-035. M $\beta$-CD, which has been used extensively as a drug delivery vehicle for its low toxicity and high solubility, was found to be quite effective in modulating the cholesterol content of tissue culture cells [25]. We optimised the concentration of $\left[3,4-{ }^{13} \mathrm{C}\right]$ cholesterol and Sandoz 58-035 and the incubation time and found that by incubating $20 \mu \mathrm{g} / \mathrm{ml}\left[3,4-{ }^{13} \mathrm{C}\right]$ cholesterol with $\mathrm{J} 774$ cells in the presence of $0.5 \mu \mathrm{g} / \mathrm{ml}$ Sandoz 58-035 for $6 \mathrm{~h}$ did not result in esterification of FC or toxicity to the cells. Under these conditions, the level of intracellular $\left[3,4-{ }^{13} \mathrm{C}\right]$ cholesterol and changes after the efflux period can be detected by LC/MS/MS. Exposure of $\left[3,4-{ }^{13} \mathrm{C}\right]$ cholesterol enriched J774 cells with HDL resulted in higher efflux than influx and a net depletion of cell cholesterol mass. Therefore, individual HDL samples were used as the extracellular acceptor for the measurement of cell cholesterol efflux.

As a powerful tool, LC/MS/MS has the ability to simultaneously identify cholesterol and stable isotope labelled cholesterol with high specificity and accurate quantification. Although cholesterol could be directly analysed by LC/MS[26], a higher sensitivity method was needed to accurately measure low levels of cell cholesterol. Therefore, we incorporated our previously used precolumn oxidation into the sample preparation, and the oxidation converts $\left[3,4-{ }^{13} \mathrm{C}\right]$ cholesterol and cholesterol to cholest-4-en-3,6-dione $[15,19]$, which has higher ionisation efficiencies than that of cholesterol and can be readily detected by LC/MS/ MS. For quantification, unlabelled cholesterol was used as the calibrator and stigmasterol was used as the internal standard. $\left[3,4-{ }^{13} \mathrm{C}\right]$ Cholesterol has the same or highly similar physical 
and chemical properties as natural cholesterol except for the mass difference. In our LC/MS/ MS method, unlabelled and labelled cholesterol have the same reaction rates, ion transitions, mass parameters and response signal in mass spectrometry and can be coeluted at the same time in chromatography. Therefore, cholesterol standard can be used to calibrate both $[3,4$ $\left.{ }^{13} \mathrm{C}\right]$ cholesterol and cholesterol itself. As the hydrolysis of cholesteryl esters, oxidation of both cholesterol and the internal standard and the chromatographic separation of cholesterol and other lipid components were included in the procedure, this method is highly specific, and the presence of sera or cell matrix did not affect the quantification of cholesterol and [3,4$\left.{ }^{13} \mathrm{C}\right]$ cholesterol concentrations.

Results from 49 healthy subjects demonstrated a negative correlation with weight, BMI, blood pressure, while a positive correlation was seen with HDL-C, HDL2-C, and apoAI levels. These results agree with previous reports[8,23]. Furthermore, HDL mediated cholesterol efflux was also negatively correlated with $\mathrm{FER}_{\mathrm{HDL}}$, a predictor of HDL function, HDL and LDL subfraction distributions and atherosclerosis $[18,20]$. These results suggest that HDL mediated cholesterol efflux measured by LC/MS/MS has a close relationship with the major CVD risk factors and could potentially be a useful marker for CVD risk assessment.

In conclusion, an LC/MS/MS method for the direct measurement of macrophage cholesterol efflux produced by HDL has been established. This method is precise, nonradioactive and is potentially useful in the assessment of HDL function and risk for cardiovascular diseases.

\section{Abbreviations}

CVD (Cardiovascular diseases); RCT (Reverse cholesterol transport); ACAT (Acyl coenzyme A: cholesterol acyltransferase); CETP (Cholesteryl ester transfer protein); LC/ MS/MS (Liquid chromatography tandem mass spectrometry); APCI (atmospheric pressure chemical ionization); MRM (multiple reaction monitoring); H-DMEM (High Dulbecco's minimal essential medium); FBS (Fetal bovine serum); PEG (polyethylene glycol); M $\beta$-CD (Methyl- $\beta$-cyclodextrin); TC (Total cholesterol); TG (Triglycerides); Glu (Glucose); FC (Free cholesterol); CE (Cholesteryl ester); LDL-C (Low-density lipoprotein cholesterol); HDL-C (High-density lipoprotein cholesterol); HDL2 (High-density lipoprotein of d 1.063-1.125 $\mathrm{kg} / \mathrm{L}$ ); HDL3 (High-density lipoprotein of d 1.125-1.210 kg/L); LDLb (Small-dense LDL); LDLa (Large-buoyant LDL); FER $_{\mathrm{HDL}}$ (Fractional esterification rate of cholesterol in HDL).

\section{Acknowledgements}

This study was supported by research grants from National Natural Science Foundation of China (30872413, 81171647, 81201337).

\section{References}

1 Gordon DJ, Rifkind BM: High-density lipoprotein — the clinical implications of recent studies. N Engl J Med 1989;321:1311-1316.

2 Barter P, Gotto AM, LaRosa JC, Maroni J, Szarek M, Grundy SM, Kastelein JJ, Bittner V, Fruchart JC: Treating to New Targets Investigators: HDL cholesterol, very low levels of LDL cholesterol, and cardiovascular events. N Engl J Med 2007;357:1301-1310.

-3 Briel M, Ferreira-Gonzalez I, You JJ, Karanicolas PJ, Akl EA, Wu P, Blechacz B, Bassler D, Wei X, Sharman A, Whitt I, Alves da Silva S, Khalid Z, Nordmann AJ, Zhou Q, Walter SD, Vale N, Bhatnagar N, O'Regan C, Mills EJ, Bucher HC, Montori VM, Guyatt GH: Association between change in high density lipoprotein cholesterol and cardiovascular disease morbidity and mortality: systematic review and meta-regression analysis. BMJ 2009;338:b92.

-4 Franceschini G, Sirtori CR, Capurso A 2nd, Weisgraber KH, Mahley RW. A-I Milano apoprotein. Decreased high density lipoprotein cholesterol levels with significant lipoprotein modifications and without clinical atherosclerosis in an Italian family. J Clin Invest 1980;66:892-900. 
5 Rothblat GH, Phillips MC: High-density lipoprotein heterogeneity and function in reverse cholesterol transport. Curr Opin Lipidol 2010;21:229-238.

6 Adorni MP, Zimetti F, Billheimer JT, Wang N, Rader DJ, Phillips MC, Rothblat GH: The roles of different pathways in the release of cholesterol from macrophages. J Lipid Res 2007;48:2453-2462.

7 de la Llera-Moya M, Drazul-Schrader D, Asztalos BF, Cuchel M, Rader DJ, Rothblat GH: The ability to promote efflux via ABCA1 determines the capacity of serum specimens with similar high-density lipoprotein cholesterol to remove cholesterol from macrophages. Arterioscler Thromb Vasc Biol 2010;30:796-801.

-8 Khera AV, Cuchel M, de la Llera-Moya M, Rodrigues A, Burke MF, Jafri K, French BC, Phillips JA, Mucksavage ML, Wilensky RL, Mohler ER, Rothblat GH, Rader DJ: Cholesterol efflux capacity, high-density lipoprotein function, and atherosclerosis. N Engl J Med 2011;364:127-135.

9 Matsuura F, Wang N, Chen W, Jiang XC, Tall AR: HDL from CETP-deficient subjects shows enhanced ability to promote cholesterol efflux from macrophages in an apoE- and ABCG1-dependent pathway. J Clin Invest 2006;116:1435-1442.

10 Yvan-Charvet L, Matsuura F, Wang N, Bamberger MJ, Nguyen T, Rinninger F, Jiang XC, Shear CL, Tall AR: Inhibition of cholesteryl ester transfer protein by torcetrapib modestly increases macrophage cholesterol efflux to HDL. Arterioscler Thromb Vasc Biol 2007;27:1132-1138.

11 Zhao Y, Van Berkel TJ, Van Eck M: Relative roles of various efflux pathways in net cholesterol efflux from macrophage foam cells in atherosclerotic lesions. Curr Opin Lipidol 2010;21:441-453.

12 Hatch FT: Practical methods for plasma lipoprotein analysis. Adv Lipid Res1968;6:1-68.

13 Briggs C, Anderson D, Johnson P, Deegan T: Evaluation of the polyethylene glycol precipitation method for the estimation of high-density lipoprotein cholesterol. Ann Clin Biochem 1981;18:177-181.

14 Brown RE, Jarvis KL, Hyland KJ: Protein measurement using bicinchoninic acid: elimination of interfering substances. Anal Biochem 1989;180:136-139.

15 Zhou W, Li H, Dong J, Wang S, Yang R, Zhang C, Chen W: Serum cholesterol measured by isotope dilution liquid chromatography tandem mass spectrometry. Clin Chem Lab Med 2011;49:669-676.

-16 Dong J, Guo H, Yang R, Li H, Wang S, Zhang J, Chen W: Serum LDL- and HDL-cholesterol determined by ultracentrifugation and HPLC. J Lipid Res 2011;52:383-388.

17 Dong J, Guo H, Yang R, Li H, Wang S, Zhang J, Zhou W, Chen W: A novel and precise method for simultaneous measurement of serum HDL and LDL subfractions and lipoprotein (a) cholesterol by ultracentrifugation and high-performance liquid chromatography. Clin Chim Acta 2012;413:1071-1076.

18 Dong J, Yu S, Yang R, Li H, Guo H, Zhao H, Wang S, Chen W: A simple and precise method for direct measurement of fractional esterification rate of high density lipoprotein cholesterol by high performance liquid chromatography. Clin Chem Lab Med 2014;52:557-564.

19 Dong J, Chen W, Wang S, Zhang J, Li H, Guo H, Man Y, Chen B: Jones oxidation and high performance liquid chromatographic analysis of cholesterol in biological samples. J Chromatogr B 2007; 5:239-46.

20 Dobiasova M, Frohlich J, Sedova M, Cheung MC, Brown BG: Cholesterol esterification and atherogenic index of plasma correlate with lipoprotein size and findings on coronary angiography. J Lipid Res 2011;52:566571.

-21 Zhang J, Cai S, Peterson BR, Kris-Etherton PM, Heuvel JP: Development of a cell-based, high-throughput screening assay for cholesterol efflux using a fluorescent mimic of cholesterol. Assay Drug Dev Technol 2011;9:136-146.

22 Sankaranarayanan S, Kellner-Weibel G, de la Llera-Moya M, Phillips MC, Asztalos BF, Bittman R, Rothblat GH: A sensitive assay for ABCA1-mediated cholesterol efflux using BODIPY-cholesterol. J Lipid Res 2011;52:2332-2340.

23 Brown RJ, Shao F, Baldan A, Albert CJ, Ford DA: Cholesterol efflux analyses using stable isotopes and mass spectrometry. Anal Bio chem 2013;433:56-64.

-24 Sankaranarayanan S, de la Llera-Moya M, Drazul-Schrader D, Asztalos BF, Weibel GL, Rothblat GH: Importance of macrophage cholesterol content on the flux of cholesterol mass. J Lipid Res 2010;51:32433249.

25 Christian AE, Haynes MP, Phillips MC, Rothblat GH: Use of cyclodextrins for manipulating cellular cholesterol content. J Lipid Res 1997;38:2264-2272.

26 Kock R, Delvoux B, Greiling H: Determination of total cholesterol in serum by liquid chromatographyisotope dilution mass spectrometry. Clin Chem 1997;43:1896-1903. 